\title{
TEffectR: An R package for studying the potential effects of transposable elements on gene expression with linear regression model
}

\author{
Gökhan Karakülah ${ }^{\text {Corresp., } 1,2}{ }^{\text {, Nazmiye Arslan }}{ }^{1}$, Cihangir Yandım ${ }^{1,3}$, Aslı Suner ${ }^{\text {Corresp. } 4}$ \\ ${ }^{1}$ Izmir Biomedicine and Genome Center, Izmir, Turkey \\ 2 Izmir International Biomedicine and Genome Institute, Dokuz Eylül University, Izmir, Turkey \\ 3 Department of Genetics and Bioengineering, Faculty of Engineering, Izmir University of Economics, Izmir, Turkey \\ 4 Department of Biostatistics and Medical Informatics / Faculty of Medicine, Ege University, Izmir, Turkey \\ Corresponding Authors: Gökhan Karakülah, Aslı Suner \\ Email address: gokhan.karakulah@deu.edu.tr, asli.suner@ege.edu.tr
}

Introduction. Recent studies highlight the crucial regulatory roles of transposable elements (TEs) on proximal gene expression in distinct biological contexts such as disease and development. However, computational tools extracting potential TE - proximal gene expression associations from RNAsequencing data are still missing.

Implementation. Herein, we developed a novel R package, using linear regression model, for studying the potential influence of TE species on proximal gene expression from a given RNA-sequencing data set. Our R package, namely TEffectR, makes use of publicly available RepeatMasker TE and Ensembl gene annotations as well as several functions of other R-packages. It calculates total read counts of TEs from sorted and indexed genome aligned BAM files provided by the user, and determines statistically significant relations between TE expression and the transcription of nearby genes under diverse biological conditions.

Availability. TEffectR is freely available at https://github.com/karakulahg/TEffectR along with a handy tutorial as exemplified by the analysis of RNA-sequencing data including normal and tumour tissue specimens obtained from breast cancer patients. 


\section{TEffectR: An $\mathbf{R}$ package for studying the potential effects of transposable}

2 elements on gene expression with linear regression model

3

4 Gökhan Karakülah ${ }^{1,2, ~ *, ~ N a z m i y e ~ A r s l a n ~}{ }^{1}$, Cihangir Yandım ${ }^{1,3}$, Aslı Suner ${ }^{4}$ *

$6 \quad{ }^{1}$ Izmir Biomedicine and Genome Center, Izmir, Turkey

$7 \quad$ 2Izmir International Biomedicine and Genome Institute, Dokuz Eylül University, Izmir, Turkey

$8{ }^{3}$ Department of Genetics and Bioengineering, Faculty of Engineering, Izmir University of

9 Economics, Izmir, Turkey

$10{ }^{4}$ Department of Biostatistics and Medical Informatics / Faculty of Medicine, Ege University, Izmir,

11 Turkey

$12 *$ Co-corresponding authors:

13 Gökhan Karakülah, E-mail: gokhan.karakulah@deu.edu.tr

14 Aslı Suner, E-mail: asli.suner@ege.edu.tr 


\section{Abstract}

16 Introduction. Recent studies highlight the crucial regulatory roles of transposable elements (TEs)

17 on proximal gene expression in distinct biological contexts such as disease and development.

18 However, computational tools extracting potential TE - proximal gene expression associations

19 from RNA-sequencing data are still missing.

20 Implementation. Herein, we developed a novel R package, using linear regression model, for 21 studying the potential influence of TE species on proximal gene expression from a given RNA22 sequencing data set. Our $\mathrm{R}$ package, namely TEffectR, makes use of publicly available

23 RepeatMasker TE and Ensembl gene annotations as well as several functions of other R-packages.

24 It calculates total read counts of TEs from sorted and indexed genome aligned BAM files provided

25 by the user, and determines statistically significant relations between TE expression and the 26 transcription of nearby genes under diverse biological conditions.

27 Availability. TEffectR is freely available at https://github.com/karakulahg/TEffectR along with a

28 handy tutorial as exemplified by the analysis of RNA-sequencing data including normal and 29 tumour tissue specimens obtained from breast cancer patients.

30 Keywords: Transposable elements, gene regulation, gene expression, regression, linear model, $\mathrm{R}$ 31 package 
36

37 Transposable elements (TEs) are DNA sequences that are able to translocate themselves along a

38 host genome (Biemont \& Vieira 2006). They were discovered by Barbara McClintock in the 1950s

39 in maize and defined for the first time as controlling elements on the action of nearby genes

40 (McClintock 1956). TEs constitute a considerable portion of most eukaryotic genomes (Kazazian

41 2004; Kelly \& Leitch 2011; Lander et al. 2001) and are divided into two main classes according

42 to their transposition mechanism (Wicker et al. 2007). Class I elements (also known as retrotransposons) use RNA intermediates and a reverse transcriptase whereas Class II elements (also known as DNA transposons) act through DNA intermediates for their translocation (Wicker et al. 2007). These mechanisms are also called as "copy-and-paste" and "cut-and-paste" transpositions, respectively. In addition to acting as key players in genome size expansion and evolution (Kazazian 2004), previous studies highlighted the critical roles of TEs in distinct biological contexts, such as cancer (Hancks \& Kazazian 2016; Johanning et al. 2017; Lee et al. 2012), embryonic development (Yandim \& Karakulah 2019), senescence and aging (De Cecco et al. 2019), and stress response (Rech et al. 2019).

In parallel to the advent of next generation sequencing technologies, considerable attention has been paid to elucidate the regulatory activities of TEs on gene expression on a genome-wide scale.

4 TEs are now recognized as the natural source of diverse regulatory sequences (Trizzino et al. 2017) including the promoters (Jordan et al. 2003), transcription factor binding sites (Bourque et al. 2008; Karakulah 2018), enhancers (Chuong et al. 2013), and silencers (Bire et al. 2016) in the host genome. For example, MER39, a human long terminal repeat (LTR), acts as an endometriumspecific promoter and plays an essential role for the expression of the prolactin gene during 
59 pregnancy (Emera et al. 2012). Similarly, an MT-C retrotransposon-derived promoter is required

60 to produce the oocyte-specific isoform of the Dicer gene in mice and its absence leads to female

61 sterility (Flemr et al. 2013). It has also been reported in a comprehensive computational study that

62 the majority of primate-specific regulatory sequences are originated from TEs (Jacques et al.

63 2013). In line with this, the influence of TEs on proximal gene expression was documented both

64 in rat (Dong et al. 2017) and maize (Makarevitch et al. 2015). Furthermore, housekeeping genes

65 were distinguished by their distinct repetitive DNA sequence environment (Eller et al. 2007).

66 When it comes to understand the links between TEs and proximal genes, it was postulated that TE

67 intermediates (DNA or RNA) may interfere with the transcription of adjacent genes either directly

68 or through recruited factors, and that an activated or repressed TE has the potential to modulate

69 the chromatin environment of such genes and thereby influence their expression states (Elbarbary

70 et al. 2016; Huda et al. 2009).

72 Despite the above-mentioned efforts on dissecting the influence of TEs on the expressions of proximal genes, a systematic and statistically valid approach was still missing, particularly due to the fact that TEs have many copies in the genome. In other words, it was challenging to link a particular TE in a specific location to a particular gene of interest. Still a notable effort has been devoted to develop computational methods on the matter. Among these, two online tools, PlanTEnrichment (Karakulah \& Suner 2017) and GREAM (Chandrashekar et al. 2015), allow their users to determine overrepresented TEs that are located adjacent of a given list of genes in plants and mammals, respectively. RTFAdb (Karakulah 2018), using transcription factor binding profiles of the Encyclopedia of DNA Elements (ENCODE) project (Consortium 2012), can be utilized for exploring the regulatory roles of TEs. TETools (Lerat et al. 2017) and RepEnrich (Criscione et al. 
82 2014) are popular computational tools to study differential expression of TEs under different

83 biological conditions. Additionally, RepEnrich can help to provide insights into the transcriptional

84 regulation of TEs by linking chromatin immunoprecipitation followed by sequencing (ChIP-seq)

85 and expression profiling data sets. However, these tools do not allow one to directly link the

86 expression of location specific TEs to a given proximal gene. Hence, we developed a novel R

87 (https://www.r-project.org) package, using linear regression model (LM), for dissecting significant

88 associations between TEs and proximal genes in a given RNA-sequencing (RNA-seq) data set.

89 Our R package, namely TEffectR, makes use of publicly available RepeatMasker TE

90 (http://www.repeatmasker.org) and Ensembl gene annotations

91 (https://www.ensembl.org/index.html)_and calculate total read counts of TEs from sorted and

92 indexed genome aligned BAM files. Then, it predicts the influence of TE expression on the

93 transcription of proximal genes under diverse biological conditions. In order to demonstrate the

94 utility of TEffectR, we examined a publicly available RNA-seq data set collected from breast

95 cancer patients. A detailed background of LM is also given in the following section.

97 Materials and Methods

98 Modeling gene expression with linear regression model

99 RNA-seq method yields count-type data rather than continuous measures of gene expression.

100 Hence, generalized linear models (GLM) are used for modeling and statistical analysis of RNA-

101 seq data sets, which are assumed to follow Poisson distribution or negative binomial distribution.

102 In order to test differential gene expression, a number of analytical methods, including edgeR

103 (Robinson et al. 2010), and DESeq2 (Oshlack et al. 2010) use GLM where expression level of 
104 each gene is modeled as response variable while biological conditions (e.g., control vs

105 experimental groups) are considered as explanatory variables or predictors. However, after the

106 transformation of RNA-seq count data to $\log 2$-counts per million ( $\log C P M)$ with Limma's voom

107 (Law et al. 2014) function, gene expression profiles can be ready for linear modelling.

108

109 LM has been used so far for modeling the regulatory effects of genetic and epigenetic factors on 110 gene expression (Gerstung et al. 2015; Li et al. 2014b). For example, Li et al. developed RACER

111 (Li et al. 2014b), using regression analysis approach, for exploring potential links between gene

112 expression levels and a number of predictors, including DNA methylation level, copy number

113 variation, transcription factor occupancy and microRNA expression level. Using a similar

114 approach, TEffectR considers given biological conditions or covariates and TE expression levels

115 as predictors to explain significant differences in gene abundances on a gene-by-gene basis.

116 TEffectR assumes that each TE has a potential to influence the expression of a proximal gene.

117 Accordingly, the expression level of a given gene can be modelled as follows:

119 Gene expression $_{i}=\beta_{0}+\beta_{1} T E_{1 i}+\cdots+\beta_{n} T E_{n i}+\beta_{m}$ Covarites $_{m i}+\varepsilon_{i}, \quad \varepsilon_{i} \sim N\left(0, \sigma^{2}\right)$

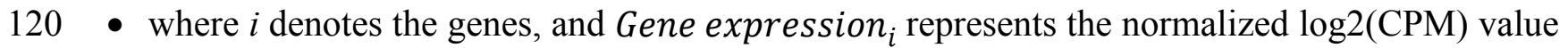

121 of the $i^{\text {th }}$ gene.

122 - $T E_{n i}$ stands for the normalized $\log 2(\mathrm{CPM})$ expression value of $\mathrm{n}^{\text {th }} \mathrm{TE}$ which is located within 123 the upstream of the $i^{\text {th }}$ gene.

124 - Covarites $m i$ indicates covariate effects in the model, such as tissue type, age, gender, etc. 


\section{Implementation of the TEffectR package}

127 The TEffectR package was written in R language (v.3.5.3) and it uses the functions of diverse

128 computational tools. To extract gene annotation data from Ensembl database and manipulation of

129 RepeatMasker annotation files, TEffectR respectively utilizes biomaRt (Durinck et al. 2009) and

130 biomartr (Drost \& Paszkowski 2017) packages. The GenomicRanges (Lawrence et al. 2013) tool

131 is used to identify TE sequences that are located in the neighborhood of the gene list provided by

132 users. For data and string manipulation steps of the TEffectR workflow, we made use of dplyr

133 (https://dplyr.tidyverse.org/), rlist (https://renkun-ken.github.io/rlist/) and stringr

134 (https://stringr.tidyverse.org/) packages. BEDtools (Quinlan 2014) and Rsamtools

135 (https://bioconductor.org/packages/release/bioc/html/Rsamtools.html) were employed for the

136 quantification of TE-derived sequencing reads in a given list of indexed and genome aligned BAM

137 files. Two popular differential gene expression analysis packages for RNA-seq data sets, edgeR

138 and limma, were used for filtering, normalization and transformation of expression values of both

139 genes and TEs. Statistical significance of each LM and covariate effect in the corresponding

140 regression model were calculated with $\operatorname{lm}()$, which is a built-in function of R.

142 Data collection and processing for case study

143 In order to demonstrate the usage of TEffectR package, we made use of a publicly available whole

144 transcriptome sequencing dataset including normal and tumour tissue specimens obtained from 22

145 ER+/HER2- breast cancer patients (GEO Accession ID: GSE103001) (Wenric et al. 2017). These

146 transcriptome libraries were particularly included as they were prepared without poly(A) selection

147 method and thereby allowing the measurement of TE expression uniformly (Solovyov et al. 2018).

148 We downloaded sequencing reads in FASTQ file format from Sequence Read Archive (Leinonen 
149 et al. 2011) (SRA Accession ID: SRP116023) using SRA Tool Kit v.2.9.0 with “fastq-dump --gzip

150 --skip-technical --readids --dumpbase --clip --split-3” command. Next, sequencing reads were

151 aligned to the human reference genome GRCh38 (Ensembl version 78) using the splice-aware

152 aligner HISAT2 v2.1.0 (Kim et al. 2015) with "hisat2 -p -dta -x \{input.index\} -1 \{input_1.fq\} -2

153 \{input_2.fq\} $-S\{$ out.sam\}" parameters. Stringtie v1.3.5 (Pertea et al. 2015) were used with

154 "stringtie -e -B -p -G \{input.gtf\} -A \{output.tab\} -o \{output.gtf\} -l \{input.label\}\{input.bam\}"

155 parameters for expression quantification at the gene level. We considered only the uniquely

156 mapped reads overlapping TE regions for the expression quantification of TEs. Multi-mapped

157 reads could cause ambiguity when analysing the local effects of TEs on proximal genes as the

158 repeats have many copies on the genome (Goerner-Potvin \& Bourque 2018; Treangen \& Salzberg

159 2011). To remove multi- and unmapped reads from BAM files, "samtools view $-b q 60$-o

$160\{$ out.bam\} \{input.bam\}" command was used. If the user would like to include the multi-mapped

161 reads, they can skip this last command.

162

\section{Results}

\section{Overview of the TEffectR package pipeline}

165 The TEffectR package includes a set of functions (Fig. 1) that allows the identification of

166 significant associations between TEs and nearby genes for any species whose repeat annotation is

167 publicly available at the RepeatMasker we

168 (http://www.repeatmasker.org/genomicDatasets/RMGenomicDatasets.html). Currently, the

169 complete annotation for over 60 species (from primates to nematodes) can be downloaded from

170 this main repository and can be analyzed with our R package. The TEffectR package works 
171 initially by manipulating the repeat annotation file and make it ready for downstream analysis. In

172 the following step, our tool takes a raw count matrix of RNA-seq dataset from the user where the

173 first column includes the gene symbols or Ensembl IDs and the other columns contain count values

174 of genes across samples. Then, TEffectR retrieves genomic position of each gene in the respective

175 genome using the given count matrix. Afterwards, based on the user-defined parameters, TEffectR

176 determines all TE species that are located within the upstream regions of each gene individually.

178 The TEffectR package contains a handy function for obtaining sequencing read counts, which are

179 aligned to each TE region from a given list of sorted and indexed BAM files. Additionally, it can

180 calculate the total read counts of each TE associated with a certain gene. In the following step,

181 TEffectR merges all read count values of both genes and TEs into a single count matrix. This count

182 matrix is then filtered, normalized with Trimmed Mean of M-values (TMM) method and

183 transformed for linear modeling using voom() function of the limma package. In the final step,

184 TEffectR fits a linear regression model with customized design matrix for each gene, and it

185 calculates adjusted R-square values and significance of the model, and estimates the model

186 parameters. The users can output the results of all calculations in tab separated values (tsv) file

187 format to assess the contribution of each covariate (e.g. individual repeats) to the model.

189 Descriptions of the functions in the TEffectR package

190 The TEffectR package provides six unique functions for predicting the potential influence of TEs

191 on the transcriptional activity of proximal genes in the respective genome: 
192 TEffectR::rm_format: This function takes RepeatMasker annotation file as input and extracts the

193 genomic location of each TE along with repeat class and family information. The output of

$194 \mathrm{rm}$ format() function is used while searching TEs that are located in the upstream region of the

195 genes of interest.

196 TEffectR::get_intervals: This function is used to retrieve the genomic locations of all genes in a

197 given read count matrix by the user. Row names of the expression matrix must be one of the

198 following: (i) official gene symbol, (ii) Ensembl gene or (iii) transcript ID. The output of this

199 function is utilized while determining distance between genes and TEs.

200 TEffectR::get_overlaps: Takes the genomic intervals of genes and TEs as input. Besides, the user

201 also requires to provide three additional parameters: (i) the maximum distance allowed between

202 the start sites of genes and TEs, (ii) whether genes and TEs must be located in same strand and

203 (iii) TE family or subfamily name (e.g. SINE, LINE). This function helps to detect TEs that are

204 localized upstream of the genes of interest. The "distance" parameter of this function could be

205 determined by the user based on the interest of the TE localization. The user can either give a

206 positive value, which would take the TEs localized in the upstream region of the gene; or a negative

207 value that would correspond to the downstream of the gene. Moreover, the absolute distance is not

208 limited; however, we used the value of "5000" to test our R package with the TEs located within

209 the $5 \mathrm{~kb}$ upstream regions of the genes, as previous studies confirmed that TEs located within $5 \mathrm{~kb}$

210 upstream of genes provide binding sites for transcription factors and provide a possible link to

211 nearby gene expression (Bourque et al. 2008; Nikitin et al. 2018). However, if the user aims to

212 study long-range effects, then the distance could be set to a higher value. 
213 TEffectR::count_repeats: This function returns a raw count matrix of the total number of reads

214 originated from TE sequences. Only the reads exhibiting 100\% overlap with given TE regions are

215 considered and the user needs to specify individual path of each BAM file as input.

216 TEffectR:: summarize_repeat_counts: Takes the output of count_repeats() function as input. It

217 is used to calculate the total number of sequencing reads derived from each TE that is located

218 upstream of a certain gene.

219 TEffectR::apply_lm: This core function applies filtering ( $\geq 10$ reads), TMM normalization, voom

220 transformation and LM to the given raw count expression values, respectively. It takes four

221 arguments: (i) raw gene counts, (ii) raw TE counts, (iii) a data frame containing user-defined

222 covariates (e.g. tissue type, disease state), and (iv) the output of get_overlaps() function. When

223 covariates are determined, one may include all the biological factors to see if they could explain

224 the expression of the gene in conjunction with TE expression. However, one may as well only use

225 the TE expression as the single predictor without the inclusion of further covariates.

227 The apply_lm() function returns three outputs: (i) a tsv file containing the p-value of each model, 228 significance level of covariates and associated adjusted $\mathrm{R}$ squared values. The generated tab 229 delimited file contains the list for the LM results of all genes that have at least one TE within the 230 region of interest as given by this function. (ii) another tsv file containing $\log 2(\mathrm{CPM})$ values of 231 genes and TEs included in LM, and (iii) a group of diagnostic plots for each significant model ( $p$ $232<0.05)$. 
234 A case example of TEffectR analysis using the RNA-seq data obtained from healthy and 235 tumour tissues of ER+/HER2- breast cancer patients

236 Breast cancer pathogenesis was associated with genomic instability (Kwei et al. 2010), which often

237 presents itself with the aberrant expression of TEs (Aguilera \& Garcia-Muse 2013; Burns 2017).

238 TEs including LINE, SINE and LTR elements were already shown to be dysregulated in this

239 disease (Bakshi et al. 2016; Bratthauer et al. 1994; Johanning et al. 2017); with little or no

240 information on the subtypes of these repeats. Also, there is a paucity of information on the impact

241 of such dysregulatory events on the expressions of genes. To demonstrate the usage of the

242 TEffectR package on a real case example, we ran the TEffectR package on the transcriptome RNA-

243 seq data set of ER+/HER2- breast cancer patients. Table 1 summarizes a group of significant genes

244 involved in breast cancer pathogenesis, diagnosis and prognosis (Abdel-Fatah et al. 2014; Chung

245 et al. 2015; Dunning et al. 2016; Forero et al. 2016; Hammerich-Hille et al. 2010; Heinrich et al.

246 2010; Heo et al. 2013; Kasper et al. 2005; Kwok et al. 2015; Li et al. 2014a; Storm et al. 1995;

247 Tang et al. 2018; Tishchenko et al. 2016; Wei et al. 2011), where TEffectR presented a linear

248 regression model that shows the associations between the expressions of these genes and that of

249 the uniquely mapped TE sequences located within their upstream 5kb flanking regions (Fig. 2).

250 These genes were only given to present a contextual example and were selected based on breast

251 cancer literature from the tab-delimited file that contains all genes with at least one TE in their

252 upstream regions. The LM could explain the effect of these TEs on the variation in gene expression

253 along with other covariates such as the type of tissue (i.e. healthy or tumour) or the individual

254 patients. For example, two of the dependent variables; the LINE element "L2b" and "Tissue type"

$255(\mathrm{p}=0.0013)$ could statistically significantly predict $70.30 \%$ of the expression of the "SLC39A6

256 (LIV-1)" gene whereas the covariate "patient" $(\mathrm{p}=0.1024)$ could not explain the variation in this 
257 particular gene's expression in this statistically significant model $(\mathrm{p}<0.001)$. On the other hand,

258 even though the expression of LTR5_Hs could predict $38.92 \%$ of "RMND1" expression

259 statistically significantly ( $<0.001$ ), neither the type of tissue (healthy or tumour; $\mathrm{p}=0.4280$ ) nor

260 the individual patient $(\mathrm{p}=0.1193)$ could explain the expression of this gene. From the perspective

261 of a molecular biologist, these results may imply that SLC39A6 gene could potentially be involved

262 in the tumorigenesis of the breast whereas this was not the case for RMND1, and the relevant

263 repeat motif upstream of both genes could be suitable for further experimental investigation in

264 terms of its potential to influence the expression of the proximal gene. These results may have

265 implications on the biological roles of TEs (e.g. L2b) on breast cancer-related gene expressions

266 (e.g. SLC39A6) and could indicate their potential roles in the carcinogenesis of the breast where

267 the tissue type (healthy vs tumour) p-value of the LM result is less than a significant threshold (i.e. $268 \mathrm{p}<0.05)$.

\section{Discussion}

271 Repetitive DNA and its regulatory effects on chromatin environment and gene expression have

272 been recognized well since the early years that follow the discovery of chromatin modifications

273 (He et al. 2019; Huda et al. 2009; Martens et al. 2005). Dynamic expression patterns of TEs during

274 distinct stages of human embryonic development (Garcia-Perez et al. 2016; Grow et al. 2015;

275 Yandim \& Karakulah 2019), where the whole genome is tightly regulated in a highly orchestrated

276 manner, and the power of TEs to modify gene expression patterns by various routes (Garcia-Perez

277 et al. 2016), highlights the importance of studying the links of TE expression with proximal gene

278 transcription. TEffectR does not only provide a linear regression model between the expression of

279 TEs and a gene in a given genomic location, but it also presents a platform to traverse this 
280 information through biological contexts such as cancer, treatment, age, etc. The option of adding

281 a desired number of covariates along with TEs that are present in a desired distance interval from

282 a given gene allows one to study the association between TEs and genes along with multiple

283 factors. Substantial studies suggest that some human gene promoters are derived from TEs (Cohen

284 et al. 2009) and that some TEs could act as distal enhancers (Kunarso et al. 2010). Still, it should

285 be noted that significant associations documented via TEffectR do not necessarily mean that a 286 given TE indeed has an influential effect on the transcription of the proximal gene. Conversely, 287 transcriptional activation of a given gene could also influence the expression of the nearby TE, 288 and the TE might not have an effect on gene expression at all. This is why functional experiments 289 should always be performed to clearly answer crucial biological questions regarding this matter, 290 where TEffectR acts as a useful guideline to point out significant associations.

\section{Conclusion}

293 The highly complex interactions among the regulatory networks of the genome are at the center of 294 attention of many areas of molecular biology, developmental biology and epigenetics. Here, we 295 presented TEffectR, an R package, which elaborately dissects the associations between the 296 expressions of genes and the transposable elements nearby them in a unified linear regression 297 model. The inclusion of a desired number of factors as covariates allows a biologist to study such 298 associations in a broader context.

300 Additional Information and Declarations

301 Acknowledgement 
302 Not applicable

303 Funding

304 There was no external funding received for this study.

305 Grant Disclosures

306 Not applicable

307 Competing Interests

308 AS is an Academic Editor for PeerJ.

309 Author Contributions

310 - GK conceived and designed the experiments, performed the experiments, analyzed the data,

311 contributed reagents/materials/analysis tools, prepared figures and/or tables, authored or reviewed

312 drafts of the paper, approved the final draft.

313 - NA contributed reagents/materials/analysis tools, authored or reviewed drafts of the paper,

314 approved the final draft.

315 CY conceived and designed the experiments, performed the experiments, analyzed the data,

316 prepared figures and/or tables, authored or reviewed drafts of the paper, approved the final draft.

317 - AS conceived and designed the experiments, analyzed the data, contributed

318 reagents/materials/analysis tools, prepared figures and/or tables, authored or reviewed drafts of the

319 paper, approved the final draft. 
321 The following information was supplied regarding data availability: GitHub:

322 https://github.com/karakulahg/TEffectR.

\section{Supplemental Information}

324 Not applicable

325

326 References

327 Abdel-Fatah TM, Russell R, Albarakati N, Maloney DJ, Dorjsuren D, Rueda OM, Moseley P, 328 Mohan V, Sun H, Abbotts R, Mukherjee A, Agarwal D, Illuzzi JL, Jadhav A, Simeonov A, Ball G, Chan S, Caldas C, Ellis IO, Wilson DM, 3rd, and Madhusudan S. 2014. Genomic and protein expression analysis reveals flap endonuclease 1 (FEN1) as a key biomarker in breast and ovarian cancer. Mol Oncol 8:1326-1338. 10.1016/j.molonc.2014.04.009

Aguilera A, and Garcia-Muse T. 2013. Causes of genome instability. Annu Rev Genet 47:1-32. 10.1146/annurev-genet-111212-133232

Bakshi A, Herke SW, Batzer MA, and Kim J. 2016. DNA methylation variation of human-specific Alu repeats. Epigenetics 11:163-173. 10.1080/15592294.2015.1130518 524. $10.1038 / 443521 \mathrm{a}$

Bire S, Casteret S, Piegu B, Beauclair L, Moire N, Arensbuger P, and Bigot Y. 2016. Mariner Transposons Contain a Silencer: Possible Role of the Polycomb Repressive Complex 2. PLoS Genet 12:e1005902. 10.1371/journal.pgen.1005902 
341 Bourque G, Leong B, Vega VB, Chen X, Lee YL, Srinivasan KG, Chew JL, Ruan Y, Wei CL, Ng 342 HH, and Liu ET. 2008. Evolution of the mammalian transcription factor binding repertoire via transposable elements. Genome Res 18:1752-1762. 10.1101/gr.080663.108

Bratthauer GL, Cardiff RD, and Fanning TG. 1994. Expression of LINE-1 retrotransposons in human breast cancer. $\quad$ Cancer 73:2333-2336.

10.1002/10970142(19940501)73:9<2333::aid-cncr2820730915>3.0.co;2-4

347 Burns KH. 2017. Transposable elements in cancer. Nat Rev Cancer 17:415-424. $10.1038 /$ nrc. 2017.35

Chandrashekar DS, Dey P, and Acharya KK. 2015. GREAM: A Web Server to Short-List Potentially Important Genomic Repeat Elements Based on Over-/Under-Representation in Specific Chromosomal Locations, Such as the Gene Neighborhoods, within or across 17 Mammalian Species. PLoS One 10:e0133647. 10.1371/journal.pone.0133647

Chung L, Onyango D, Guo Z, Jia P, Dai H, Liu S, Zhou M, Lin W, Pang I, Li H, Yuan YC, Huang Q, Zheng L, Lopes J, Nicolas A, Chai W, Raz D, Reckamp KL, and Shen B. 2015. The FEN1 E359K germline mutation disrupts the FEN1-WRN interaction and FEN1 GEN activity, causing aneuploidy-associated cancers. Oncogene 34:902-911. 10.1038/onc.2014.19 genes: a critical assessment. Gene 448:105-114. 10.1016/j.gene.2009.06.020 
363 Consortium EP. 2012. An integrated encyclopedia of DNA elements in the human genome. Nature 364 489:57-74. 10.1038/nature11247

365 Criscione SW, Zhang Y, Thompson W, Sedivy JM, and Neretti N. 2014. Transcriptional landscape of repetitive elements in normal and cancer human cells. BMC Genomics 15:583. $10.1186 / 1471-2164-15-583$

De Cecco M, Ito T, Petrashen AP, Elias AE, Skvir NJ, Criscione SW, Caligiana A, Brocculi G, 369 Adney EM, Boeke JD, Le O, Beausejour C, Ambati J, Ambati K, Simon M, Seluanov A, Gorbunova V, Slagboom PE, Helfand SL, Neretti N, and Sedivy JM. 2019. L1 drives IFN in senescent cells and promotes age-associated inflammation. Nature 566:73-78. $10.1038 / \mathrm{s} 41586-018-0784-9$

373 374

Dong Y, Huang Z, Kuang Q, Wen Z, Liu Z, Li Y, Yang Y, and Li M. 2017. Expression dynamics and relations with nearby genes of rat transposable elements across 11 organs, 4 developmental stages and both sexes. BMC Genomics 18:666. 10.1186/s12864-017-40787

Drost HG, and Paszkowski J. 2017. Biomartr: genomic data retrieval with R. Bioinformatics 33:1216-1217. 10.1093/bioinformatics/btw821

Dunning AM, Michailidou K, Kuchenbaecker KB, Thompson D, French JD, Beesley J, Healey CS, Kar S, Pooley KA, Lopez-Knowles E, Dicks E, Barrowdale D, Sinnott-Armstrong NA, Sallari RC, Hillman KM, Kaufmann S, Sivakumaran H, Moradi Marjaneh M, Lee JS, Hills M, Jarosz M, Drury S, Canisius S, Bolla MK, Dennis J, Wang Q, Hopper JL, Southey MC, Broeks A, Schmidt MK, Lophatananon A, Muir K, Beckmann MW, Fasching PA, DosSantos-Silva I, Peto J, Sawyer EJ, Tomlinson I, Burwinkel B, Marme F, Guenel P, Truong T, Bojesen SE, Flyger H, Gonzalez-Neira A, Perez JI, Anton-Culver H, Eunjung L, Arndt 
MA, Yoon SY, Friedman E, Laitman Y, Borg A, von Wachenfeldt A, Ehrencrona H, Rantala J, Olopade OI, Ganz PA, Nussbaum RL, Gayther SA, Nathanson KL, Domchek SM, Arun BK, Mitchell G, Karlan BY, Lester J, Maskarinec G, Woolcott C, Scott C, Stone J, Apicella C, Tamimi R, Luben R, Khaw KT, Helland A, Haakensen V, Dowsett M, Pharoah PD, Simard J, Hall P, Garcia-Closas M, Vachon C, Chenevix-Trench G, Antoniou AC, Easton DF, and Edwards SL. 2016. Breast cancer risk variants at 6q25 display

417 Durinck S, Spellman PT, Birney E, and Huber W. 2009. Mapping identifiers for the integration of genomic datasets with the R/Bioconductor package biomaRt. Nat Protoc 4:1184-1191.

Elbarbary RA, Lucas BA, and Maquat LE. 2016. Retrotransposons as regulators of gene expression. Science 351:aac7247. 10.1126/science.aac 7247

Eller CD, Regelson M, Merriman B, Nelson S, Horvath S, and Marahrens Y. 2007. Repetitive sequence environment distinguishes housekeeping genes. Gene 390:153-165. 10.1016/j.gene.2006.09.018

Emera D, Casola C, Lynch VJ, Wildman DE, Agnew D, and Wagner GP. 2012. Convergent evolution of endometrial prolactin expression in primates, mice, and elephants through the independent recruitment of transposable elements. Mol Biol Evol 29:239-247. 10.1093/molbev/msr189

Flemr M, Malik R, Franke V, Nejepinska J, Sedlacek R, Vlahovicek K, and Svoboda P. 2013. A 430 retrotransposon-driven dicer isoform directs endogenous small interfering RNA production in mouse oocytes. Cell 155:807-816. 10.1016/j.cell.2013.10.001 
432 Forero A, Li Y, Chen D, Grizzle WE, Updike KL, Merz ND, Downs-Kelly E, Burwell TC,

433 Vaklavas C, Buchsbaum DJ, Myers RM, LoBuglio AF, and Varley KE. 2016. Expression

434 of the MHC Class II Pathway in Triple-Negative Breast Cancer Tumor Cells Is Associated

435 with a Good Prognosis and Infiltrating Lymphocytes. Cancer Immunol Res 4:390-399.

436 10.1158/2326-6066.CIR-15-0243

437 Garcia-Perez JL, Widmann TJ, and Adams IR. 2016. The impact of transposable elements on 438 mammalian development. Development 143:4101-4114. 10.1242/dev.132639

439 Gerstung M, Pellagatti A, Malcovati L, Giagounidis A, Porta MG, Jadersten M, Dolatshad H, 440 Verma A, Cross NC, Vyas P, Killick S, Hellstrom-Lindberg E, Cazzola M, Papaemmanuil $10.1038 /$ ncomms6901

444 Goerner-Potvin P, and Bourque G. 2018. Computational tools to unmask transposable elements. Nat Rev Genet 19:688-704. 10.1038/s41576-018-0050-x

Grow EJ, Flynn RA, Chavez SL, Bayless NL, Wossidlo M, Wesche DJ, Martin L, Ware CB, Blish CA, Chang HY, Pera RA, and Wysocka J. 2015. Intrinsic retroviral reactivation in human preimplantation embryos and pluripotent cells. Nature 522:221-225. 10.1038/nature14308

Hammerich-Hille S, Kaipparettu BA, Tsimelzon A, Creighton CJ, Jiang S, Polo JM, Melnick A, 450 Meyer R, and Oesterreich S. 2010. SAFB1 mediates repression of immune regulators and apoptotic genes in breast cancer cells. $J$ Biol Chem 285:3608-3616. 10.1074/jbc.M109.066431

Hancks DC, and Kazazian HH, Jr. 2016. Roles for retrotransposon insertions in human disease. Mob DNA 7:9. 10.1186/s13100-016-0065-9 
455 He J, Fu X, Zhang M, He F, Li W, Abdul MM, Zhou J, Sun L, Chang C, Li Y, Liu H, Wu K, 456 Babarinde IA, Zhuang Q, Loh YH, Chen J, Esteban MA, and Hutchins AP. 2019.

457

458

459

460

461

462

463

464

465

466

467

468

469

470

471

472

473

474

475

Transposable elements are regulated by context-specific patterns of chromatin marks in mouse embryonic stem cells. Nat Commun 10:34. 10.1038/s41467-018-08006-y

Heinrich C, Keller C, Boulay A, Vecchi M, Bianchi M, Sack R, Lienhard S, Duss S, Hofsteenge J, and Hynes NE. 2010. Copine-III interacts with ErbB2 and promotes tumor cell migration. Oncogene 29:1598-1610. 10.1038/onc.2009.456

Heo CK, Hwang HM, Ruem A, Yu DY, Lee JY, Yoo JS, Kim IG, Yoo HS, Oh S, Ko JH, and Cho EW. 2013. Identification of a mimotope for circulating anti-cytokeratin 8/18 antibody and its usage for the diagnosis of breast cancer. Int J Oncol 42:65-74. 10.3892/ijo.2012.1679

Huda A, Marino-Ramirez L, Landsman D, and Jordan IK. 2009. Repetitive DNA elements, nucleosome binding and human gene expression. Gene 436:12-22. 10.1016/j.gene.2009.01.013

Jacques PE, Jeyakani J, and Bourque G. 2013. The majority of primate-specific regulatory sequences are derived from transposable elements. PLoS Genet 9:e1003504. 10.1371/journal.pgen.1003504

Johanning GL, Malouf GG, Zheng X, Esteva FJ, Weinstein JN, Wang-Johanning F, and Su X. 2017. Expression of human endogenous retrovirus-K is strongly associated with the basallike breast cancer phenotype. Sci Rep 7:41960. 10.1038/srep41960

Jordan IK, Rogozin IB, Glazko GV, and Koonin EV. 2003. Origin of a substantial fraction of human regulatory sequences from transposable elements. Trends Genet 19:68-72.

PeerJ reviewing PDF | (2019:08:40301:1:1:NEW 12 Oct 2019) 
476 Karakulah G. 2018. RTFAdb: A database of computationally predicted associations between 477 retrotransposons and transcription factors in the human and mouse genomes. Genomics 478 110:257-262. 10.1016/j.ygeno.2017.11.002

479

480

481

482

483

484

485

486

487

488

489

490

491

492

493

494

495

496 elements in plants. Genomics 109:336-340. 10.1016/j.ygeno.2017.05.008

Kasper G, Weiser AA, Rump A, Sparbier K, Dahl E, Hartmann A, Wild P, Schwidetzky U, Castanos-Velez E, and Lehmann K. 2005. Expression levels of the putative zinc transporter LIV-1 are associated with a better outcome of breast cancer patients. Int J Cancer 117:961973. 10.1002/ijc. 21235

Kazazian HH, Jr. 2004. Mobile elements: drivers of genome evolution. Science 303:1626-1632. $10.1126 /$ science. 1089670

Kelly LJ, and Leitch IJ. 2011. Exploring giant plant genomes with next-generation sequencing technology. Chromosome Res 19:939-953. 10.1007/s10577-011-9246-z

Kim D, Langmead B, and Salzberg SL. 2015. HISAT: a fast spliced aligner with low memory requirements. Nat Methods 12:357-360. 10.1038/nmeth.3317

Kunarso G, Chia NY, Jeyakani J, Hwang C, Lu X, Chan YS, Ng HH, and Bourque G. 2010. Transposable elements have rewired the core regulatory network of human embryonic stem cells. Nat Genet 42:631-634. 10.1038/ng.600

Kwei KA, Kung Y, Salari K, Holcomb IN, and Pollack JR. 2010. Genomic instability in breast cancer: pathogenesis and clinical implications. Mol Oncol 4:255-266. 10.1016/j.molonc.2010.04.001 
497 Kwok HF, Zhang SD, McCrudden CM, Yuen HF, Ting KP, Wen Q, Khoo US, and Chan KY.

498 2015. Prognostic significance of minichromosome maintenance proteins in breast cancer.

$499 \quad$ Am J Cancer Res 5:52-71.

500 Lander ES, Linton LM, Birren B, Nusbaum C, Zody MC, Baldwin J, Devon K, Dewar K, Doyle

501 M, FitzHugh W, Funke R, Gage D, Harris K, Heaford A, Howland J, Kann L, Lehoczky J,

502 LeVine R, McEwan P, McKernan K, Meldrim J, Mesirov JP, Miranda C, Morris W, Naylor

503 J, Raymond C, Rosetti M, Santos R, Sheridan A, Sougnez C, Stange-Thomann Y,

504 Stojanovic N, Subramanian A, Wyman D, Rogers J, Sulston J, Ainscough R, Beck S,

505 Bentley D, Burton J, Clee C, Carter N, Coulson A, Deadman R, Deloukas P, Dunham A,

506 Dunham I, Durbin R, French L, Grafham D, Gregory S, Hubbard T, Humphray S, Hunt A,

507 Jones M, Lloyd C, McMurray A, Matthews L, Mercer S, Milne S, Mullikin JC, Mungall

508 A, Plumb R, Ross M, Shownkeen R, Sims S, Waterston RH, Wilson RK, Hillier LW,

509 McPherson JD, Marra MA, Mardis ER, Fulton LA, Chinwalla AT, Pepin KH, Gish WR,

510 Chissoe SL, Wendl MC, Delehaunty KD, Miner TL, Delehaunty A, Kramer JB, Cook LL,

511 Fulton RS, Johnson DL, Minx PJ, Clifton SW, Hawkins T, Branscomb E, Predki P,

512 Richardson P, Wenning S, Slezak T, Doggett N, Cheng JF, Olsen A, Lucas S, Elkin C,

513 Uberbacher E, Frazier M, Gibbs RA, Muzny DM, Scherer SE, Bouck JB, Sodergren EJ,

514 Worley KC, Rives CM, Gorrell JH, Metzker ML, Naylor SL, Kucherlapati RS, Nelson DL,

515 Weinstock GM, Sakaki Y, Fujiyama A, Hattori M, Yada T, Toyoda A, Itoh T, Kawagoe

516 C, Watanabe H, Totoki Y, Taylor T, Weissenbach J, Heilig R, Saurin W, Artiguenave F,

517 Brottier P, Bruls T, Pelletier E, Robert C, Wincker P, Smith DR, Doucette-Stamm L,

518 Rubenfield M, Weinstock K, Lee HM, Dubois J, Rosenthal A, Platzer M, Nyakatura G,

519 Taudien S, Rump A, Yang H, Yu J, Wang J, Huang G, Gu J, Hood L, Rowen L, Madan A, 

M, Grimwood J, Cox DR, Olson MV, Kaul R, Raymond C, Shimizu N, Kawasaki K, Minoshima S, Evans GA, Athanasiou M, Schultz R, Roe BA, Chen F, Pan H, Ramser J, Lehrach H, Reinhardt R, McCombie WR, de la Bastide M, Dedhia N, Blocker H, Hornischer K, Nordsiek G, Agarwala R, Aravind L, Bailey JA, Bateman A, Batzoglou S, RR, Doerks T, Eddy SR, Eichler EE, Furey TS, Galagan J, Gilbert JG, Harmon C, Hayashizaki Y, Haussler D, Hermjakob H, Hokamp K, Jang W, Johnson LS, Jones TA, Kasif S, Kaspryzk A, Kennedy S, Kent WJ, Kitts P, Koonin EV, Korf I, Kulp D, Lancet D, Lowe TM, McLysaght A, Mikkelsen T, Moran JV, Mulder N, Pollara VJ, Ponting CP, Schuler G, Schultz J, Slater G, Smit AF, Stupka E, Szustakowki J, Thierry-Mieg D, Thierry-Mieg J, Wagner L, Wallis J, Wheeler R, Williams A, Wolf YI, Wolfe KH, Yang SP, Yeh RF, Collins F, Guyer MS, Peterson J, Felsenfeld A, Wetterstrand KA, Patrinos A, Morgan MJ, de Jong P, Catanese JJ, Osoegawa K, Shizuya H, Choi S, Chen YJ, Szustakowki J, and International Human Genome Sequencing C. 2001. Initial sequencing and analysis of the human genome. Nature 409:860-921. 10.1038/35057062

Law CW, Chen Y, Shi W, and Smyth GK. 2014. voom: Precision weights unlock linear model analysis tools for RNA-seq read counts. Genome Biol 15:R29. 10.1186/gb-2014-15-2-r29

Lawrence M, Huber W, Pages H, Aboyoun P, Carlson M, Gentleman R, Morgan MT, and Carey VJ. 2013. Software for computing and annotating genomic ranges. PLoS Comput Biol 9:e1003118. 10.1371/journal.pcbi.1003118

Lee E, Iskow R, Yang L, Gokcumen O, Haseley P, Luquette LJ, 3rd, Lohr JG, Harris CC, Ding L, Wilson RK, Wheeler DA, Gibbs RA, Kucherlapati R, Lee C, Kharchenko PV, Park PJ, and 
Cancer Genome Atlas Research N. 2012. Landscape of somatic retrotransposition in human cancers. Science 337:967-971. 10.1126/science.1222077

545 Leinonen R, Sugawara H, Shumway M, and International Nucleotide Sequence Database C. 2011. The sequence read archive. Nucleic Acids Res 39:D19-21. 10.1093/nar/gkq1019

547 Lerat E, Fablet M, Modolo L, Lopez-Maestre H, and Vieira C. 2017. TEtools facilitates big data expression analysis of transposable elements and reveals an antagonism between their

Li C, Bai J, Hao X, Zhang S, Hu Y, Zhang X, Yuan W, Hu L, Cheng T, Zetterberg A, Lee MH, 551 and Zhang J. 2014a. Multi-gene fluorescence in situ hybridization to detect cell cycle gene copy number aberrations in young breast cancer patients. Cell Cycle 13:1299-1305.

Li Y, Liang M, and Zhang Z. 2014b. Regression analysis of combined gene expression regulation $10.4161 /$ cc. 28201 in acute myeloid leukemia. PLoS Comput Biol 10:e1003908. 10.1371/journal.pcbi.1003908

Makarevitch I, Waters AJ, West PT, Stitzer M, Hirsch CN, Ross-Ibarra J, and Springer NM. 2015. Transposable elements contribute to activation of maize genes in response to abiotic stress. PLoS Genet 11:e1004915. 10.1371/journal.pgen.1004915

561

Martens JH, O'Sullivan RJ, Braunschweig U, Opravil S, Radolf M, Steinlein P, and Jenuwein T. 561 2005. The profile of repeat-associated histone lysine methylation states in the mouse epigenome. EMBO J 24:800-812. 10.1038/sj.emboj.7600545 21:197-216. 
565 Nikitin D, Penzar D, Garazha A, Sorokin M, Tkachev V, Borisov N, Poltorak A, Prassolov V, and

566

567

568

569

570

571

572

573

574

575

576

577

578

579

580

581

582

583

584 585

586

587

Buzdin AA. 2018. Profiling of Human Molecular Pathways Affected by Retrotransposons at the Level of Regulation by Transcription Factor Proteins. Front Immunol 9:30. 10.3389/fimmu.2018.00030

Oshlack A, Robinson MD, and Young MD. 2010. From RNA-seq reads to differential expression results. Genome Biol 11:220. 10.1186/gb-2010-11-12-220

Pertea M, Pertea GM, Antonescu CM, Chang TC, Mendell JT, and Salzberg SL. 2015. StringTie enables improved reconstruction of a transcriptome from RNA-seq reads. Nat Biotechnol 33:290-295. 10.1038/nbt.3122

Quinlan AR. 2014. BEDTools: The Swiss-Army Tool for Genome Feature Analysis. Curr Protoc Bioinformatics 47:11 12 11-34. 10.1002/0471250953.bi1112s47

Rech GE, Bogaerts-Marquez M, Barron MG, Merenciano M, Villanueva-Canas JL, Horvath V, Fiston-Lavier AS, Luyten I, Venkataram S, Quesneville H, Petrov DA, and Gonzalez J. 2019. Stress response, behavior, and development are shaped by transposable elementinduced mutations in Drosophila. PLoS Genet 15:e1007900. 10.1371/journal.pgen.1007900

Robinson MD, McCarthy DJ, and Smyth GK. 2010. edgeR: a Bioconductor package for differential expression analysis of digital gene expression data. Bioinformatics 26:139-140. 10.1093/bioinformatics/btp616

Solovyov A, Vabret N, Arora KS, Snyder A, Funt SA, Bajorin DF, Rosenberg JE, Bhardwaj N, Ting DT, and Greenbaum BD. 2018. Global Cancer Transcriptome Quantifies Repeat Element Polarization between Immunotherapy Responsive and T Cell Suppressive Classes. Cell Rep 23:512-521. 10.1016/j.celrep.2018.03.042 
588 Storm FK, Gilchrist KW, Warner TF, and Mahvi DM. 1995. Distribution of Hsp-27 and HER$5892 /$ neu in in situ and invasive ductal breast carcinomas. Ann Surg Oncol 2:43-48.

590 Tang X, Zhang H, Long Y, Hua H, Jiang Y, and Jing J. 2018. PARP9 is overexpressed in human 591 breast cancer and promotes cancer cell migration. Oncol Lett 16:4073-4077. 592 $10.3892 / 01.2018 .9124$

593 Tishchenko I, Milioli HH, Riveros C, and Moscato P. 2016. Extensive Transcriptomic and 594 Genomic Analysis Provides New Insights about Luminal Breast Cancers. PLoS One 11:e0158259. 10.1371/journal.pone.0158259

Treangen TJ, and Salzberg SL. 2011. Repetitive DNA and next-generation sequencing: computational challenges and solutions. Nat Rev Genet 13:36-46. 10.1038/nrg3117

Trizzino M, Park Y, Holsbach-Beltrame M, Aracena K, Mika K, Caliskan M, Perry GH, Lynch VJ, and Brown CD. 2017. Transposable elements are the primary source of novelty in primate gene regulation. Genome Res 27:1623-1633. 10.1101/gr.218149.116

Wei L, Liu TT, Wang HH, Hong HM, Yu AL, Feng HP, and Chang WW. 2011. Hsp27 participates in the maintenance of breast cancer stem cells through regulation of epithelialmesenchymal transition and nuclear factor-kappaB. Breast Cancer Res 13:R101.

Wenric S, ElGuendi S, Caberg JH, Bezzaou W, Fasquelle C, Charloteaux B, Karim L, Hennuy B, 606 Freres P, Collignon J, Boukerroucha M, Schroeder H, Olivier F, Jossa V, Jerusalem G, Josse C, and Bours V. 2017. Transcriptome-wide analysis of natural antisense transcripts 
609 Wicker T, Sabot F, Hua-Van A, Bennetzen JL, Capy P, Chalhoub B, Flavell A, Leroy P, Morgante

610 M, Panaud O, Paux E, SanMiguel P, and Schulman AH. 2007. A unified classification 611 system for eukaryotic transposable elements. Nat Rev Genet 8:973-982. 10.1038/nrg2165

612 Yandim C, and Karakulah G. 2019. Expression dynamics of repetitive DNA in early human 613 embryonic development. BMC Genomics 20:439. 10.1186/s12864-019-5803-1 


\section{Table $\mathbf{1}$ (on next page)}

Examples of significant associations of LINE, SINE, LTR and DNA transposons with genes that were previously linked to breast cancer as TEffectR outputs along with multiple covariates.

Expression levels of TEs within the upstream $5 \mathrm{~kb}$ regions of the given genes and other covariates such as the tissue type (healthy vs. tumor) or patient number were included in the linear regression model. The $p$-value of the model indicates the significance of the linear model. P-values for each covariate indicate whether these have significant associations with the expression of the given gene respectively. Adjusted r-square score indicates the precision of the model with significant covariate associations in terms of predicting the expression of the gene. For example, an adjusted $\mathrm{R}$ square of 0.8422 indicates that the linear model could explain $84.22 \%$ of the gene's expression. 


\begin{tabular}{|c|c|c|c|c|c|c|}
\hline Link to breast cancer & Gene name & TE name & r squared & Adjusted r-squared & Model p-value & Individual p-values \\
\hline Biomarker $^{1}$ & KRT8 (CK8) & L2c (LINE) & 0.8532 & 0.8422 & $1.026 \mathrm{E}-16$ & $\begin{array}{l}\text { L2c: } 1.356 \mathrm{E}-13 \\
\text { Tissue type: } 0.0332 \\
\text { Patient: } 0.7974\end{array}$ \\
\hline Prognosis $^{2}$ & SLC39A6 (LIV-1) & $\begin{array}{l}\text { L2b } \\
(\text { LINE) }\end{array}$ & 0.7231 & 0.7023 & $3.100 \mathrm{E}-11$ & $\begin{array}{l}\text { L2b: 7.536E- } 08 \\
\text { Tissue type: } 0.0013 \\
\text { Patient: } 0.1024\end{array}$ \\
\hline Molecular pathogenesis $^{3}$ & SAFB & L1MB7 (LINE) & 0.5131 & 0.4766 & $2.107 \mathrm{E}-06$ & $\begin{array}{l}\text { L1MB7: } 1.114 \mathrm{E}-07 \\
\text { Tissue type: } 0.6112 \\
\text { Patient: } 0.1394\end{array}$ \\
\hline Susceptibility $^{4}$ and prognosis ${ }^{5}$ & CHEK2 & $\begin{array}{l}\text { AluJb, AluSx AluS } \\
\text { (SINE) }\end{array}$ & 0.6362 & 0.5883 & $1.645 \mathrm{E}-07$ & $\begin{array}{l}\text { AluJb: } 0.0433 \\
\text { AluSx: } 0.0426 \\
\text { AluSz: } 0.0005 \\
\text { Tissue type: } 0.0023 \\
\text { Patient: } 0.0033\end{array}$ \\
\hline Susceptibility $^{6}$ and prognosis ${ }^{7}$ & FEN1 & $\begin{array}{l}\text { MIR3 } \\
\text { (SINE) }\end{array}$ & 0.5545 & 0.5211 & $3.703 \mathrm{E}-07$ & $\begin{array}{l}\text { MIR3: 2.572E-06 } \\
\text { Tissue type: } 0.0122 \\
\text { Patient: } 0.3886\end{array}$ \\
\hline $\begin{array}{l}\text { Molecular genetics and } \\
\text { pathogenesis }^{8}\end{array}$ & CENPL & $\begin{array}{l}\text { AluSx3, AluY } \\
\text { (SINE) }\end{array}$ & 0.5489 & 0.5027 & $2.118 \mathrm{E}-06$ & $\begin{array}{l}\text { AluSx3: } 0.0007 \\
\text { AluY: } 0.2000 \\
\text { Tissue type: } 0.0066 \\
\text { Patient: } 0.2467\end{array}$ \\
\hline
\end{tabular}




\begin{tabular}{|c|c|c|c|c|c|c|}
\hline Prognosis $^{9}$ & MCM4 & $\begin{array}{l}\text { MLT1D } \\
\text { (LTR) }\end{array}$ & 0.5733 & 0.5413 & $1.587 \mathrm{E}-07$ & $\begin{array}{l}\text { MLT1D: } 0.0012 \\
\text { Tissue type: } 1.544 \mathrm{E}-06 \\
\text { Patient: } 0.1674\end{array}$ \\
\hline Susceptibility $^{10}$ & RMND1 & $\begin{array}{l}\text { LTR5_Hs } \\
\text { (LTR) }\end{array}$ & 0.4318 & 0.3892 & $4.279 \mathrm{E}-05$ & $\begin{array}{l}\text { LTR5_Hs: } 1.782 \mathrm{E}-05 \\
\text { Tissue type: } 0.4280 \\
\text { Patient: } 0.1193\end{array}$ \\
\hline $\begin{array}{l}\text { Molecular pathogenesis and } \\
\text { prognosis }^{11}\end{array}$ & CPNE3 & $\begin{array}{l}\text { MLT1H2 } \\
\text { (LTR) }\end{array}$ & 0.3910 & 0.3453 & 0.0002 & $\begin{array}{l}\text { MLT1H2: } 0.0002 \\
\text { Tissue type: } 0.0055 \\
\text { Patient: } 0.9407\end{array}$ \\
\hline Biomarker and prognosis $^{12}$ & HLA-DPB1 & $\begin{array}{l}\text { hAT-1_Mam } \\
\text { (DNA) }\end{array}$ & 0.8318 & 0.8192 & $1.548 \mathrm{E}-15$ & $\begin{array}{l}\text { hAT-1_Mam: } 1.092 \mathrm{E}-14 \\
\text { Tissue type: } 0.5467 \\
\text { Patient: } 0.2850\end{array}$ \\
\hline $\begin{array}{l}\text { Molecular pathogenesis }{ }^{13} \text { and } \\
\text { biomarker }^{14}\end{array}$ & HSPB2 (HSP27) & $\begin{array}{l}\text { MER5B } \\
\text { (DNA) }\end{array}$ & 0.7756 & 0.7587 & $4.791 \mathrm{E}-13$ & $\begin{array}{l}\text { MER5B: } 8.050 \mathrm{E}-07 \\
\text { Tissue type: } 0.5756 \\
\text { Patient: } 0.1733\end{array}$ \\
\hline Molecular pathogenesis $^{15}$ & PARP9 & $\begin{array}{c}\text { MER5B } \\
\text { (DNA) }\end{array}$ & 0.5929 & 0.5624 & $6.287 \mathrm{E}-08$ & $\begin{array}{l}\text { MER5B: } 1.141 \mathrm{E}-06 \\
\text { Tissue type: } 0.0054 \\
\text { Patient: } 0.5464\end{array}$ \\
\hline $\begin{array}{l}{ }^{1} \text { (Heo et al. 2013) } \\
2 \text { (Kasper et al. 2005) } \\
{ }^{3} \text { (Hammerich-Hille et al. 2010) } \\
{ }^{4} \text { (Nagel et al. 2012) } \\
5 \text { (Li et al. 2014) }\end{array}$ & $\begin{array}{l}{ }^{6} \text { (Chung } \\
7 \text { (Abdel- } \\
{ }^{8} \text { (Tishch } \\
9 \text { (Kwok } \\
{ }^{9} \text { (Dunni }\end{array}$ & $\begin{array}{l}\text { 15) } \\
\text { al. 2014) } \\
\text { al. 2016) } \\
15) \\
2016)\end{array}$ & $\begin{array}{l}11 \\
12 \\
13 \\
14 \\
15\end{array}$ & $\begin{array}{l}\text { al. 2010) } \\
1.2016) \\
2011) \\
\text {.1995) } \\
\text { 2018) }\end{array}$ & & \\
\hline
\end{tabular}




\section{Figure 1}

Figure 1.

The workflow of TEffectR package. The package contains six core functions for the identification of the potential links between TEs and nearby genes at genome wide. TEffectR requires two inputs provided by the user: (i) a raw gene count matrix and (ii) genomic alignments of sequencing reads in BAM file format. 
1. Download and parse RepeatMasker annotation rm_format() function

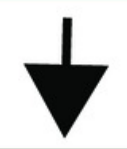

3. Identify TEs overlapping within the upstream of given genes get_overlaps() function

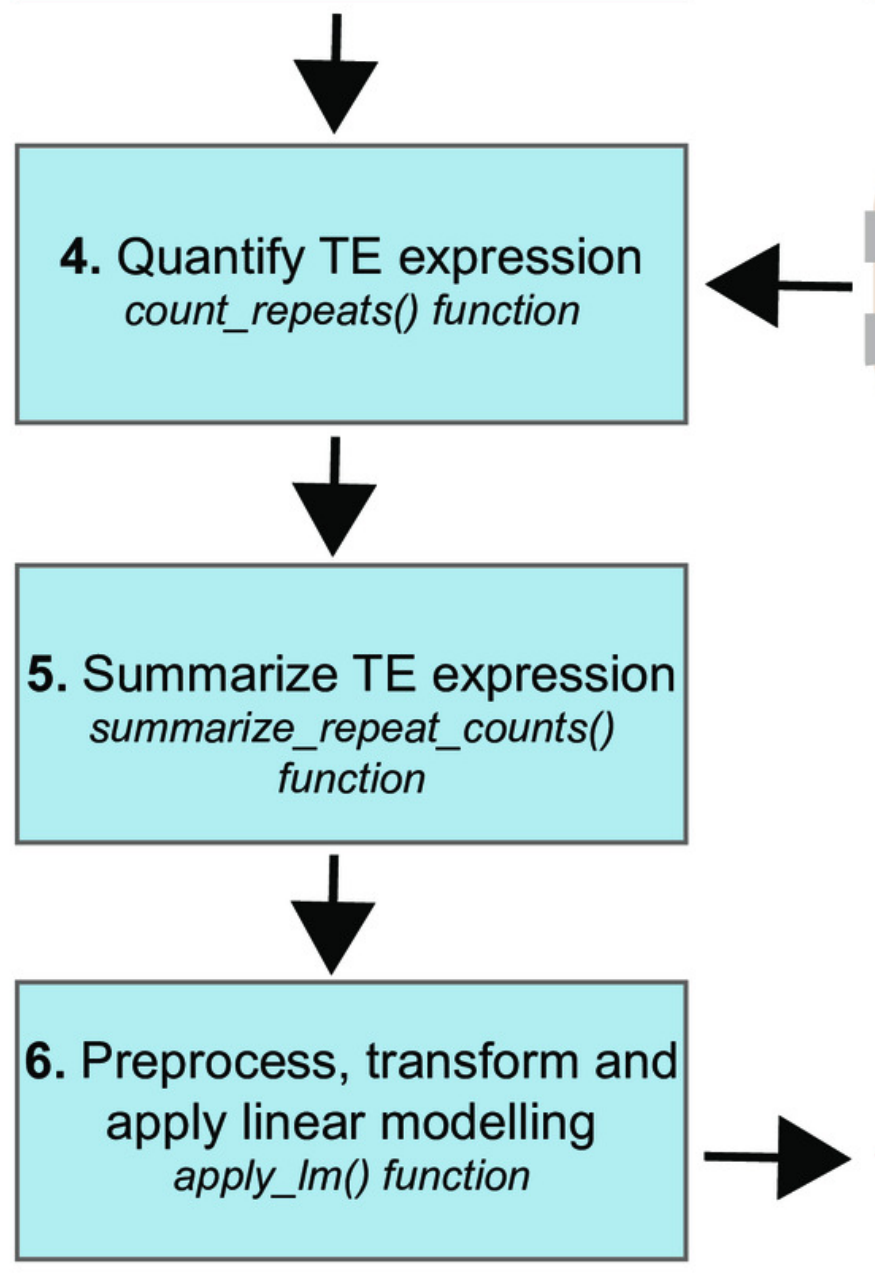

Raw gene counts (provided by the user)

2. Retrieve gene annotation from Ensembl database get_intervals() function input BAM Files (provided by the user)
Significant associations 
Figure 2

Figure 2.

Scatter plots that demonstrate the correlations of normalized read counts of genes given in Table-1 with the normalized read counts of TEs present in their upstream 5-kb regions. (CPM: counts per million)
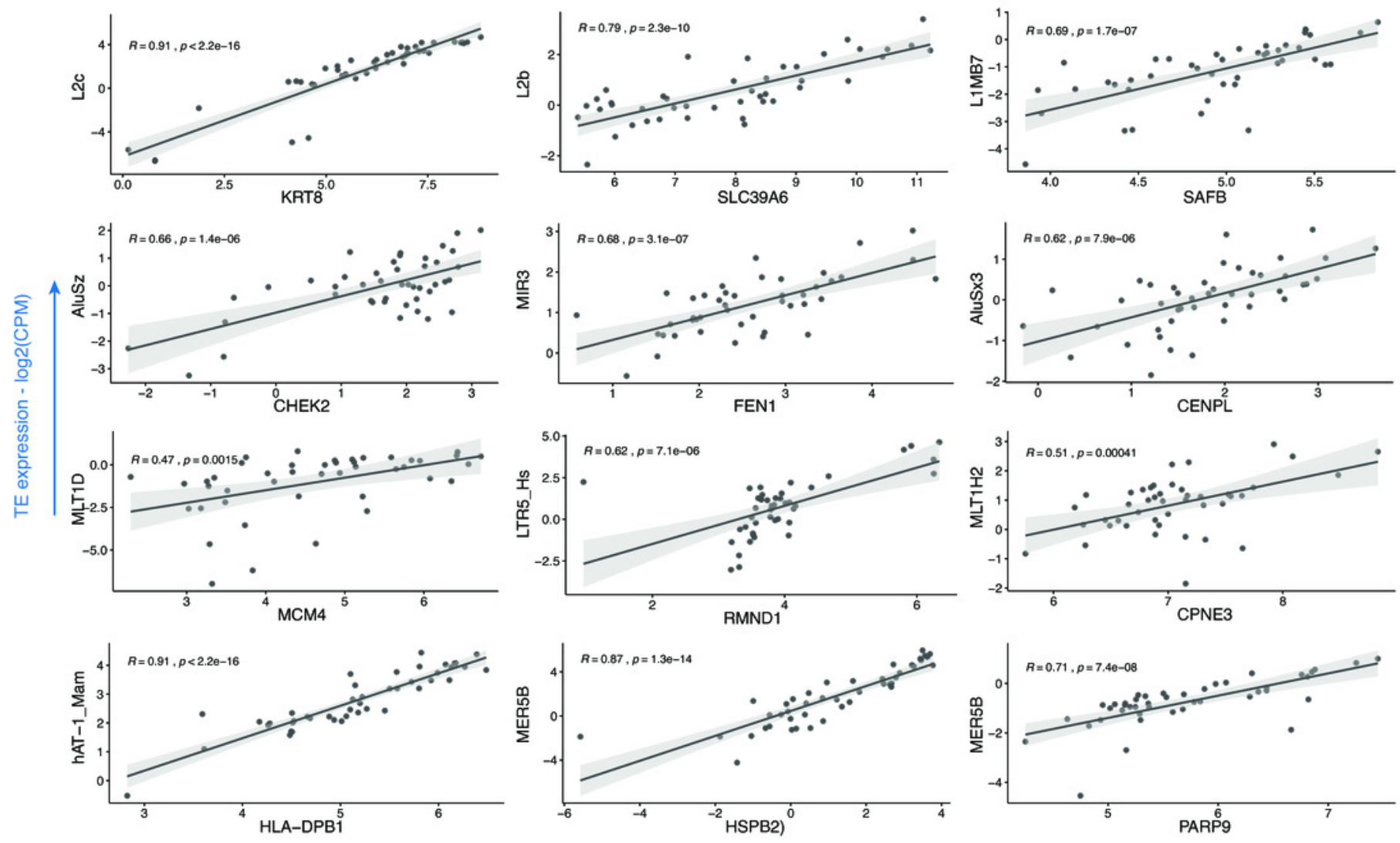

gene expression - $\log 2(\mathrm{CPM})$ 